\title{
Impact Analysis of Integrated Project Delivery on the Value of Construction Project in China
}

\author{
Tingting Mei, a , Qiankun Wang ${ }^{1, b}$ and Zeng Guo ${ }^{1, c}$ \\ ${ }^{1}$ Department of management engineering, Wuhan university of technology, Wuhan, China \\ a22243571@qq.com, bwangqk@whut.edu.cn, c527869953@qq.com
}

Keywords: Integrated project delivery, Construction project, China, Impact analysis

\begin{abstract}
Building information modeling (BIM) technology can effectively solve the problem of information sharing in construction project, but its benefit has not been maximized due to the lack of matching delivery. Even integrated project delivery (IPD) creates the collaborative environment for BIM, part of the IPD principles are still not yet implemented due to the unique present situation of construction industry and the bidding system in China. This paper has preliminarily explored the impact of the IPD principles on the value of the construction project in China via a questionnaire survey. The result shows that the practitioners of the construction industry in China basically think that the principles of IPD has a positive impact on the value of the construction project. Therefore, the purpose of the paper is to provide theoretical support for the feasibility of application of IPD in China and effective suggestions for the specific implementation of its principles.
\end{abstract}

\section{Introduction}

With the increasing complexity of construction projects and growing demand of the owners, the disadvantages of traditional project delivery mode are also increasingly prominent. Especially, the phenomenon of "information island" hindered the efficient collaborative work between participants is getting more and more serious. By solving the problem of information sharing in the construction project, building information modeling (BIM) provides a new opportunity to improve the efficiency and effectiveness of the construction process [1]. The research results from Dodge Data \& Analytics showed that the number of construction enterprises in China with high utility ration of BIM (using BIM in more than $30 \%$ projects) will be increased by $108 \%$ in the next two years, ranking among the top five fastest growing areas of BIM applications [2]. However, due to the lack of matching delivery, the benefit of BIM technology has not been maximized.

In view of the separation of many contracts, the split of delivery such as DBB obviously destroyed the collaborative environment of the application of BIM [3]. Considering the contractual agreement of stakeholders, even if the DB model has a more fluent flow of information, it is still not suitable for the use of BIM [4]. As a result, integrated project delivery (IPD) arises as a new model. IPD eliminates the drawbacks of DBB and DB, while BIM is considered to be the essential condition for promoting IPD to achieve coordination [5]. The combination of IPD with collaboration as the core and BIM represented by the information technology, not only effectively solves the problem of low level of informatization and poor management methods in China's construction industry, but also improves work efficiency and adds the value of construction projects through collaborative work.

Because of the unique present situation of construction industry and the bidding system in China, part of the IPD principles such as aligning multi-party agreements, sharing financial risk and reward based on project outcome, etc. are still not yet implemented. At present, it mainly stays in the conceptual phase in our country. Due to the back of systematic understanding and popularization of the concept of IPD, the practitioners who use the part of the IPD principles do not understand their acts belong to the category of using IPD. Therefore, this paper has preliminarily explored the impact 
of the IPD principles on the value of the construction project in China via a questionnaire survey. The purpose of the paper is to provide theoretical support for the feasibility of application of IPD in China and effective suggestions for the specific implementation of its principles.

\section{The Evolution of IPD Principles}

In 2006, the Construction Users Round Table(CURT), the Associated General Contractors of America(AGC) and the American Institute of Architects(AIA) discussed the report on the results of the principles of IPD, listed a total of 21 principles for the implementation of IPD [6]. According to the nature of the assigned projects' actual work, the principles can be divided into five categories: the actual organization and process, the scope of project work, the measurement of project outcomes, the tools and methods, and the contract agreement. Combined with the engineering practice, it makes people understand the principle of IPD more deeply.

At present, there is no unified definition of IPD. Meanwhile, there are still some disputes about the definition of IPD in the academic area [7]. One of the most widely accepted definition in construction industry is in "Integrated Project Delivery: A Guide" released by AIA in 2007. IPD is a project delivery approach that integrates people, system, business structures and practices into a process that collaboratively harnesses the talents and insights of all participants to optimize project results, increase value to the owner, reduce waste, and maximize efficiency through all phases of design, fabrication, and construction [8]. It simplifies the principles from 21 to 9, and gives the implementation suggestions from the aspects of organization construction, the mechanism of sharing risk and reward, etc.. By comparing the process of the traditional delivery modes, it not only redefines the process of IPD, and also defines its essence as a formation of a real cooperation which changes the hostile relationship between traditional construction project participants.

In 2008, AIA released a case studies which summarized 32 project leaders' practical experience of applying 9 principles of IPD in the process of implementing IPD [9]. It included project organization and management, budgeting and management, contract, BIM model and so on.

In 2010, the National Association of State Facilities Administrators (NASFA), the Construction Owners Association of America (COAA), American Higher Education Management Association (APPA), AIA, and AGC defines IPD for public and private owners [10]. It offers a tiered approach to achieving collaboration based on three levels, namely typical collaboration, enhanced collaboration and required collaboration. The levels of collaboration depends on the degree of application of principle of IPD. Based on the levels of collaboration, IPD is divides into two areas: IPD as a philosophy (non-multi party contracts or typical collaboration or enhanced collaboration), and IPD as a delivery method (multi-party contracts or required collocation).

\section{Research Methodology}

Hypothetical Condition. Based on the actual situation of construction industry in China, there is still no real pure project of IPD at present. According to the levels of collaboration, China is in the stage of take IPD as a philosophy. Therefore, the following assumptions are presented in this paper: First, taken a variety of factors into consideration, the 15 principles of IPD from "Integrated Project Delivery for Public and Private Owners" are selected as the research object. Second, according to the actual situation of construction project, the project manager can use selectively the principles of IPD. Third, the introduction of principles of IPD in construction project can create value.

Questionnaire Survey. In order to analyze the influence of principles of IPD on the value of the construction project in China, a survey is conducted through the questionnaire of the practical application of principles of IPD. These issues related to this paper include: First, what is your company type? Second, how many years do you work in the related fields (less than 3 years; 3 to 5 years; 6 to 9 years; 10 to 15 years; more than 15 years)? Third, how familiar are you with IPD (those who are experience with IPD; those who are inexperienced though informed about IPD; and those that are inexperienced and unfamiliar with IPD)? Fourth, based on the actual situation of China, how do 
you think the following principles have an impact on the value of the construction project (very negative; more negative; no influence; more active; very positive)? The paper designed a rectangular questionnaire which took the 15 principles in Table 1 as the longitudinal axis, and 5 influence degree as the horizontal axis.

The questionnaires are issued through conferences, e-mail, network platform and so on. The respondents who consist of the project participants, managers of trade and industry association, researcher in universities or research institutes will not be restricted in domestic geographical area. Ultimately, 225 questionnaires were sent out, of which 205 efficient questionnaires were received with 91.1 percent retrieving rate. In order to ensure the results of questionnaire to be consistent with the actual situation, in this paper we are going to adopt two kinds of filtered data samples: the average level sample (ALA) included both those informed about IPD or not, and the best level of sample (BLA) represented those who are experience with IPD or inexperienced though informed about IPD.

Table 1. The classification of principles of IPD

\begin{tabular}{cccc}
\hline Number & Classification & Principle & Abbreviation \\
\hline 1 & Contractual & Key participants bound together as equals & KPBTE \\
2 & principles & Liability waivers between key participants & LWKP \\
3 & & Early involvement of key participants & EIKP \\
4 & & Fiscal transparency between key participants & FT \\
5 & & Jointly developed project target criteria & JDPTC \\
6 & & Shared financial risk and reward based on project outcome & SRR \\
7 & & Intensified design & ID \\
8 & & Collaborative decision-making & CDM \\
9 & Behavioral & Mutual respect and trust & MRT \\
10 & principles & Willingness to collaborate & WTC \\
11 & & Open communication & OC \\
12 & Catalysts for & Multi-party agreement & MA \\
13 & IPD & Building information modeling & BIM \\
14 & & Lean design and construction & LC \\
15 & & Co-location of team & CT \\
\hline
\end{tabular}

\section{Results and Analysis}

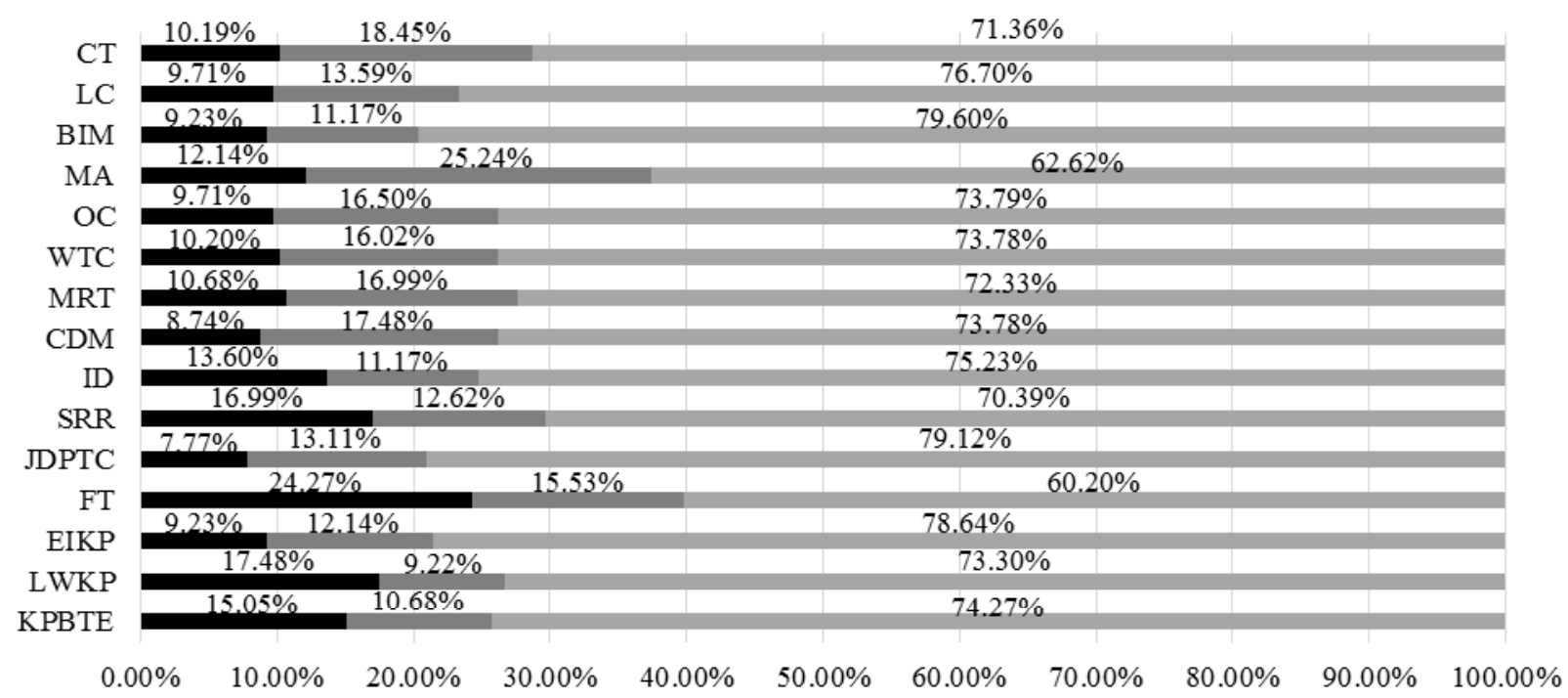

- negative influence no influence $\quad$ positive influence

Figure 1. The influence of principles of IPD on the value of construction project in ALA 


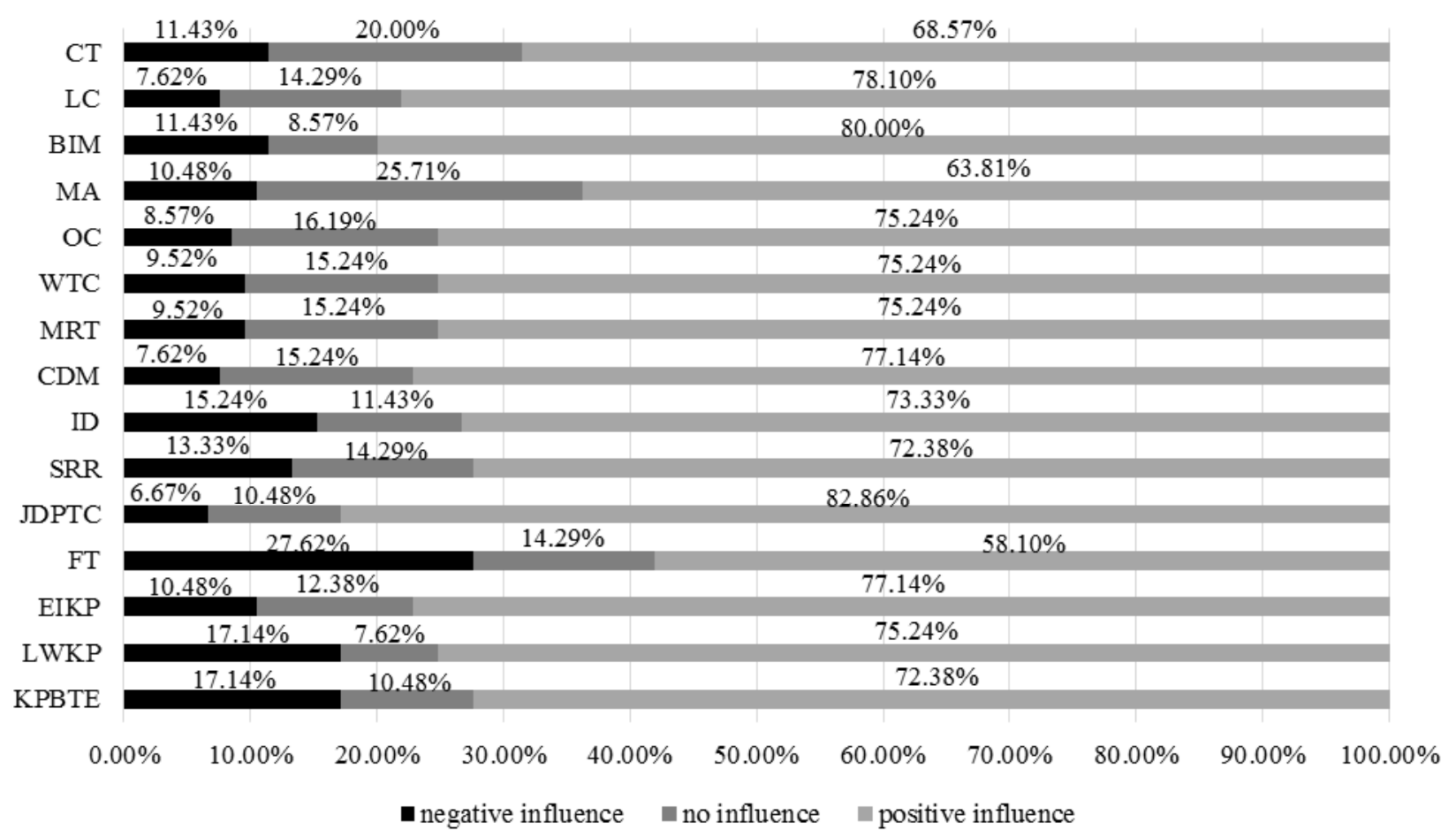

Figure 2. The influence of principles of IPD on the value of construction project in BLA If $\{$ very negative, more negative $\} \epsilon$ negative influence and $\{$ more active, very positive $\} \epsilon$ positive influence, the paper summarizes the data of ALA and BLA and draws the corresponding Stacked Bar Graph. As Figure1 and 2 show, the respondents of ALA and BLA generally believe that the principles of IPD has a more positive influence on the value of the construction project. Through the comparative analysis of the results in Figure 1 and Figure 2, the paper makes a ranking for the influence of IPD on the value of the construction project in China.

\section{Discussion of results}

By comparing the results of the ALA and BLA, the following conclusion can be obtained.

The Same Conclusion. First, the respondents had a more optimistic attitude towards the impact of IPD on the value of the construction project in China. Second, the negative influence ranking of the principles of IPD lists FT, KPBTE, LWKP, SRR, ID and so on. Therefore, this five principles of IPD are considered to have the greatest negative impact on the value of the construction project for ALA and BLA. Third, the positive influence ranking of the principles of IPD lists EIKP, JDPTC, BIM, LC and so on. Therefore, this principles of IPD are considered to have the greatest positive impact on the value of the construction project for ALA and BLA.

The Different Conclusions. First, compared with BLA, the respondents of ALA believe that the negative effects of the principles of BIM and CT are slightly smaller. The result shows that the principles of BIM and CT are expected to be applied by the respondents of ALA who think they can improve the value of construction project. For the principle of CDM, the respondents of ALA think it hasn't a very significant impact on the value of the construction project. However, the respondents of BLA have a negative opinion on it and think the principle of CDM is more important. Second, compared with ALA, the respondents of BLA insist that the negative effect of the principle of BIM is similar to the principle of CT. It shows that the respondents of BLA believe the application of BIM and Co-location of team need to complement each other, in order to achieve collaborative work. The principles of LWKP, MRT, WTC and OC close to the rankings which shows the respondents think these principles are equally important and all have a positive impact on the value of the construction project. 


\section{Conclusions}

At present, the practitioners of the construction industry in China basically think that the principles of IPD has a positive impact on the value of the construction project. Those who are experience with IPD or are inexperienced though informed about IPD attach more importance to the principles of collaborative ideas, such as CDM. Those who have experience on IPD or not are still looking forward to using BIM. In addition, the negative effects of the principles of FT, LWKP and SRR are relatively large on the value of the construction project. Because these principles do not conform to the current situation of the construction industry in China, they are less likely to be implemented at present, so the practitioners need to strengthen their understanding of these principles. The principles of EIKP and JDPTC both create the basic conditions for collaborative work to which BIM and LC provide technical support. So, these principles have been widely recognized. However, this research is limited by the amount and geography of sample, the timeliness of the data and so on. Whether it is legislative restrictions, policy limitations, cultural barriers or the application of BIM, this paper need further research on how to apply the principles of IPD in construction project in China.

\section{Acknowledgements}

This work was financially supported by the project of science and technology plan of Wuhan Urban and Rural Construction Commission (201530).

\section{References}

[1] W. Shou et al., Arch Computat Methods Eng Vol. 22(2015), p. 291.

[2] DODGE Data \& Analytics: Research Report on the application value of BIM in China (Dodge Data \&Analytics, Bedford, Massachusetts, 2015).

[3] N. S. Chougule, B. A. Konnur. International Journal of Innovative Research in Advanced Engineering Vol. 2(2015), p. 98.

[4] C. Estaman, P. Teicholz, R. Sacks, K. Liston: BIM Handbook A Guide to Building Information Modelling for Owners, Managers, Designers, Engineers, and Contractors (John Wiley \& Sons, Inc.,USA, 2008).

[5] U. Isikdag, J. Underwood: A Synopsis of the Handbook of Research on Building Information Modellling (Proceedings of CIB World Building Congress W78 Track, 2010)

[6] 3Xpt Strategy Group Integrated Project Delivery Workshop.Integrated Project Delivery:First Principles for Owners and Teams [EB/OL]. https://www.agc.org/sites/default/files/Files/Programs\%20\%26\%20Industry\%20Relations/2008070 7\%203xPT\%20IPDW\%20final.pdf

[7] QH.He, Q.He. Project Management Vol. 2 (2016), p. 20.

[8] The American Institute of Architects (AIA), California Council (2007), Integrated Project Delivery: A Guide, Version 1, The American Institute of Architects (AIA), California Council, CA, available at: www.aia.org/contractdocs/AIASO77630 (accessed March 1, 2015)

[9] AIA(The American Institute of Architects).Experiences in Collaboration: On the Path to IPD,AIA California,2009.

[10] NASFA,COAA,APPA,AGC and AIA. Integrated Project delivery for public and private owners[EB/OL].www.agc.org/projectdelivery. 